\title{
A GIS Methodology for Planning Sustainable Renewable Energy Deployment in Portugal
}

\author{
Paula Costa, Teresa Simões, Ana Estanqueiro \\ Laboratório Nacional de Energia e Geologia-LNEG, Lisboa, Portugal \\ Email: paula.alexandracosta@lneg.pt, teresa.simoes@lneg.pt, ana.estan queiro@lneg.pt
}

How to cite this paper: Costa, P., Simões, T. and Estanqueiro, A. (2019) A GIS Methodology for Planning Sustainable Renewable Energy Deployment in Portugal. Energy and Power Engineering, 11, 379-391. https://doi.org/10.4236/epe.2019.1112025

Received: September 11, 2019

Accepted: December 16, 2019

Published: December 19, 2019

Copyright $\odot 2019$ by author(s) and Scientific Research Publishing Inc. This work is licensed under the Creative Commons Attribution International License (CC BY 4.0).

http://creativecommons.org/licenses/by/4.0/

\begin{abstract}
A Geographical Information System (GIS) methodology was developed to identify and characterize suitable areas for deploying renewable energy projects. The methodology enables to compute the sustainable renewable energy potential in an area under study and can be implemented for different spatial scales, ranging from local to national levels, while operating with different restriction layers. This GIS-based method has been successfully applied to wind energy deployment studies in Continental Portugal and other foreign countries (e.g. Venezuela, Mozambique among others). Results from several development plans using this methodology enable to conclude it is an adequate tool for planning sustainable renewable energy deployment both for onshore and offshore regions.
\end{abstract}

\section{Keywords}

Planning, Sustainable Potential, GIS, Renewable Energy, Wind Energy

Deployment

\section{Introduction}

During the latest years, Portugal had a remarkable growth in the deployment of renewable energies (RE) due to the adoption of favorable legislation framework by the Portuguese government under the European Union energy policy. During 2013 the Portuguese government approved the new National Renewable Energy Action Plan [1] establishing a threshold of 5273 MW (by the year 2020) for the onshore installed wind power. As in other European Member states, Portugal is developing its National Plan for Energy and Climate (PNEC2030) [2], following the new European Commission Directive for Renewable Energy-Recast to 2030 (RED II) [3], and establishes very ambitious targets for renewable energy deployments (for wind energy, 8-9 GW, approximately, are foreseen until 2030). New and updated methodologies together with new regulations are though needed to comply with the established targets. 
By the end of 2013, the total installed capacity in Portugal reached $4707 \mathrm{MW}$ (23\% of the total capacity installed in Portugal) [4] while in the end of 2017 the total installed capacity reaches $5313 \mathrm{MW}$ [5] with a wind energy yearly penetration of $24 \%$ only surpassed by Denmark [5]. Although Portugal has acceptably good endogenous resources for exploiting REs the areas still available for new deployments are, becoming scarce therefore tools to identify available locations with good energy indicators are necessary.

In order to support policy makers and investors several GIS planning tools have been developed in recent years for assessing the sustainable potential of REs for several countries e.g. Spain [6] and US [7]. In addition, these planning methodologies were applied at regional scales [8] [9]. All these models take into account the various land uses, the wind resource-data from mesoscale modeling - and the environmental restrictions. In this line of work, LNEG's activity started in the early 90's with the development of the first wind energy database in Portugal, EOLOS [10] followed by EOLOS-2 [11]. These databases were developed in a Microsoft Access platform with SQL language with the ability to perform simple queries to the locally geo-referenced wind information. These databases do not provide or enabled spatial operations between data.

More recently, building on the historic knowledge of the REs resources over Portugal, the research goals were widened to include the spatial mapping of the onshore wind resource and the first Portuguese Wind Atlas [12] [13] [14] [15] and the Offshore Wind Atlas in 2006 [16]. Although the published studies were more focused on the development of wind resource atlases and therefore they do not include crucial information for planning purposes (e.g. physical and geographic constraints).

In this sense GIS studies were developed to obtain the sustainable availability of the renewable wind potential in Portuguese territory for the onshore case [17] and for the offshore case [18]. Section 2 of the paper provides a brief background of the REs methodology developed. Section 3 presents the results obtained with the methodology proposed for application to the wind energy Portuguese case study. Along the Section 4 a description of the GIS operation is provided and Section 5 presents the calculation of the sustainable REs potential for the wind energy case study. Finally, in Section 6 some conclusions are drawn.

\section{Methodology}

The proposed methodology requires the use of a GIS platform able to combine the use of different spatial operations taking into account the layers with constraints information and the renewable energy resource map. The methodology is divided in four sub-models applied sequentially. The first sub-model, inputs the constraint layers (environment, terrain slope, wind speed and wind energy resoure map) and compute the sustainable area which are the "free" areas adequate for wind park deployment. The second sub-model computes the soil occupation factors. The soil occupation factor corresponds to the normalized value of the number of inhabitants per kilometer squared per each administrative re- 
gion. The third model computes for each area the total installed wind park capacity operating per each administrative region and the last model, computes the sustainable available potential per each administrative region. The output of this GIS methodology enables to identify the: a) best areas and the regions most adequate to energy deployments; and b) total sustainable renewable potential still available for the identified zones, according to the input premises classified onto to the restriction areas. Although the methodology can be applied to any spatially variable form of RE, this paper focuses on its development for the wind energy sector, using mainland Portugal as a case study. Figure 1 illustrates the methodology structure.

\subsection{Renewable Energy Resource Definition}

The base information for the application of the methodology is the development of (or assessment to) a geo-referenced resource map, usually defined as a resource atlas. This map constitutes the source information to which the exclusion criteria-associated with the n-dimensional layers of constraints-are applied thus assessing the final sustainable potential for each renewable form of energy. The resource map needs to reflect the economic sustainability of deploying a specific RE technology, thus an effective straightforward approach is to define a threshold condition that guarantees a minimum economic profitability of the technology under study, e.g. its annual equivalent number of hours at full capacity for wind turbines (NEPs). A database with the coordinates and nominal power of all wind power plants already operating (or under project) is also required and included in an additional GIS-layer. Table 1 shows the information required for input into the GIS methodology.

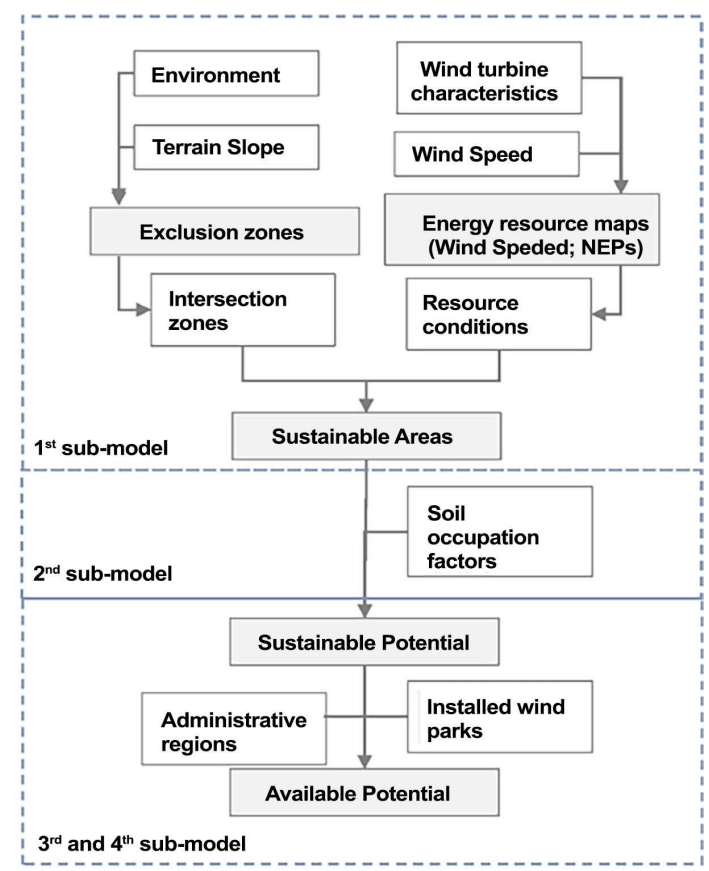

Figure 1. Methodology structure for the wind energy available potential assessment. 
Table 1. Information required for GIS Methodology—renewable energy resource.

\begin{tabular}{cll}
\hline & - Energy resource map(s) from a renewable energy atlas \\
& - & Minimum threshold condition value (e.g. Minimum mean \\
Information required for & & wind speed $(\mathrm{m} / \mathrm{s})$ or NEPs (h/year)) \\
The GIS methodology: & - Reference wind turbine (WT) nominal power \\
& - Existing (under project) REs power plants \\
& - Equivalent renewable energy losses factor (MWh) \\
\hline
\end{tabular}

\subsection{Criteria Classes and Spatial Definition Layers}

To determine possible available areas, layers with human geography data such as administrative regions (districts, municipalities), roads and urban areas, among others, are ingested in-to the GIS. Physical geography information e.g. rivers, lagoons, terrain slope. Furthermore, the methodology incorporates information related to environment restrictions, such as, natural parks, protected heritage, and similar.

The regional social-economic occupation was taken into consideration. The occupation factors were defined according to the demographic classification of the area under study, e.g. number of inhabitants per $\mathrm{km}^{2}$ ). The occupation factors are then classified from 0 to 1 , where 0 means extremely dense occupation and 1 means extremely reduced populated areas. Table 2 shows the main spatial information and criteria classes for the GIS methodology application for the Portuguese onshore wind energy case study.

The methodology operates by integrating the information presented in Table 1 and Table 2 into a GIS platform. A set of models was programmed and organized in a designed toolbar that enables to identify available areas for the deployment of REs projects (wind energy, in the present case study) and, as a by-product to compute the sustainable REs capacity in each of those areas. In the current case study, the sustainable wind capacity can be mathematically expressed by the following expression:

$$
P_{i}=\alpha \beta \gamma_{i} \eta_{i} \varepsilon_{i}-w_{i}
$$

where, $P_{i}$ represents the sustainable wind power (in MW) per identified area or polygon and

$$
\begin{gathered}
\alpha=\mathrm{EL} \\
\beta=\frac{\mathrm{Pot}}{8760} \\
\gamma_{i}=\mathrm{SO}_{i} \\
\eta_{i}=\frac{d x d y}{\delta x \delta y D^{2}} \\
\varepsilon_{i}=\sum_{j=1}^{N_{i}} \mathrm{NEPs}_{j i} \\
w_{i}=\sum_{j=1}^{k} \mathrm{MW}_{j i}
\end{gathered}
$$


Table 2. Spatial information and criteria classes for GIS methodology.

\begin{tabular}{cll}
\hline Orography: & - Terrain slope \\
Environmental: & - & Natural parks; Natura 2000 \\
& Protected heritage \\
Soil occupation: & - & Avery low populated; low populated \\
& - & Very high populated high populated \\
\hline
\end{tabular}

The parameters involved in Equations (2) to (7) are expressed below:

EL: coefficient for equivalent potential energy losses;

Pot: nominal power of a reference turbine (MW) used to compute the wind energy resource map in hours per year;

8760: the number of hours in a year;

$\mathrm{SO}_{i}$ : soil occupation factor for polygon $i$;

$D x d y$ : pixel area in the wind energy resource map (in meters);

$\delta x \delta y D^{2}$ land area required by each wind turbine, expressed as a multiple of rotor diameter $D$, where $\delta x, \delta y$ represent the minimum distances for crosswind and along wind directions respectively (in meters);

$\mathrm{NEPs}_{j i}$ : NEPs map raster value after applying all GIS exclusions in grid point $j$ inside polygon $i$

$N_{i}$ : number of grid points inside polygon $i$;

$\mathrm{MW}_{j i}$ : nominal power (MW) from each wind farm operating inside polygon $i$;

$k$. total number of wind farms inside polygon $i$.

\section{The Portuguese Wind Resource Case Study}

\subsection{Resource Map: The Portuguese Wind Atlas}

The resource map used as input for the Portuguese wind case study was obtained by numerical modeling of the atmospheric flow [12] [13] [14]. The resource map was computed at a spatial grid of $100 \times 100 \mathrm{~m}$ having as reference a $2.0 \mathrm{MW}$ nominal power wind turbine model. The wind energy resource map depicted in Figure 2 was processed for a standard height of $80 \mathrm{~m}$ above ground level and expressed in NEPs (h/year)

\subsection{Terrain Slope}

The terrain slope for the Portuguese territory was derived from a processed raster terrain database obtained by the Shuttle Radar Topography Mission SRTM30-Plus [19] [20]. For this case study, areas with slope values greater than $20 \%$ was exclude. Figure 3 shows the slope terrain in map in percent units used in the study.

\subsection{Environment Restrictions}

The Portuguese territory has specific legislation for areas inside the country that are protected and classified as "Natural Parks" and "Natura 2000" areas. Figure 4 


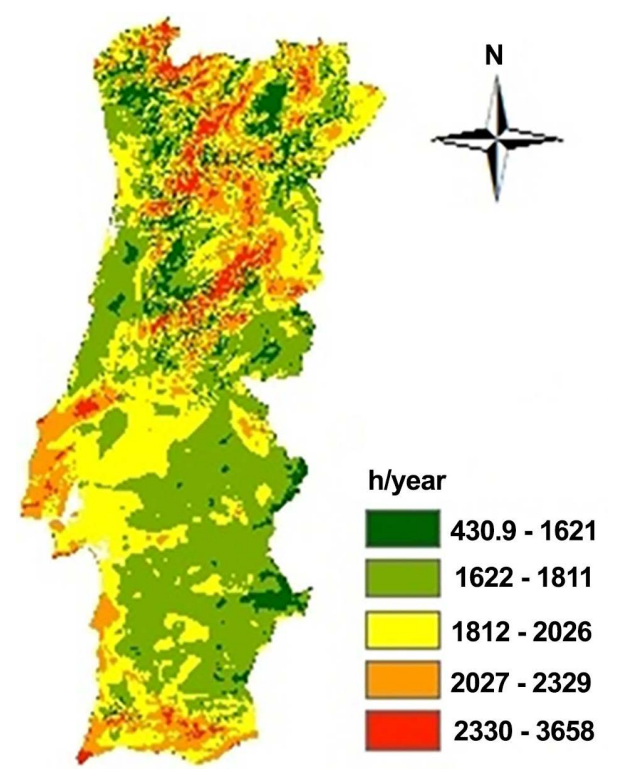

Figure 2. Spatial distribution of NEP's (h/year) over Portugal Mainland.

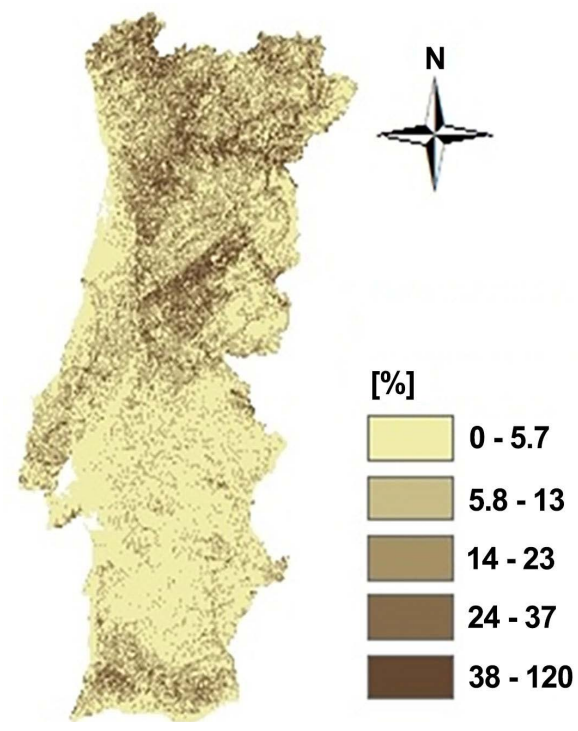

Figure 3. Raster map of the terrain slope (\%).

depicts all these environmental areas. Although these areas are classified as restricted there are some zones inside of them that may be used for wind energy exploitation with very low occupancy rates. For the case of "Natural Parks" an occupancy of $1 \%$ to $2 \%$ is assumed as acceptable. For the "Natura 2000 " areas, and depending on the characteristics of each area, the occupation cannot exceed $25 \%$.

\subsection{Soil Occupation}

The soil occupation should reflect the roughness of the terrain and the impact of the existing social economic activities. Roughness information can be provided 


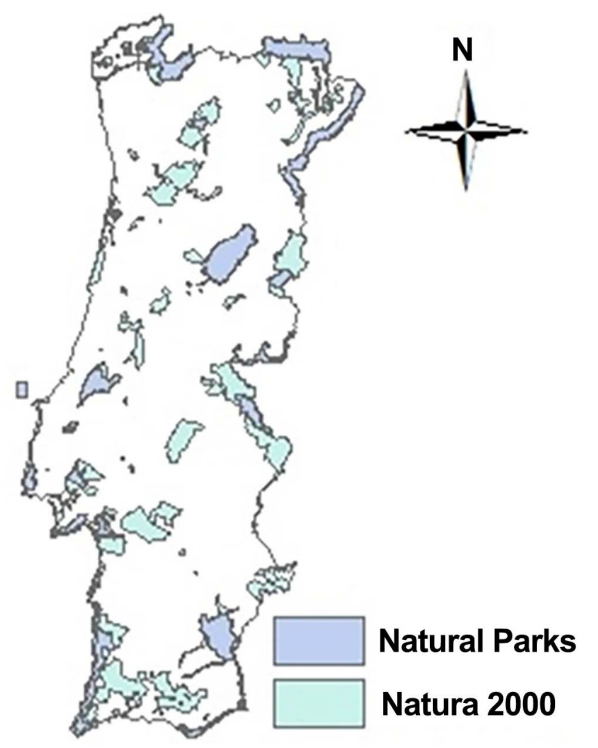

Figure 4. Environnemental areas (source http://www.icnf.pt).

by tabular values commonly used in wind engineering studies [21] [22] whose values were used in the previous wind energy resource assessment studies $(\$ 3.1$ Wind Resource). For the Soil Occupation classification, a coefficient factor was defined for each administrative region depending on demography, namely the population occupation percentile, as in Table 3. The population occupation percentile was computed from the number of inhabitants per squared $\mathrm{km}$ per administrative area and the occupation factor corresponds to the normalized value of the number of habitants per squared $\mathrm{km}$ per each administrative region. In Figure 5 the soil occupation factors are depicted.

\subsection{Active Installed Wind Parks}

As part of the identification of the wind power capacity still available in each administrative region, it is mandatory to obtain information about the total wind capacity already installed. For the present case study, the most up to date information was gathered by municipality based in information provided both from DGEG institution (http://www.dgeg.pt) and by the annual publications of the International Energy Agency [3].

\section{GIS Application}

\subsection{Model Development}

The model development for the integration of the methodology into the GIS platform was performed with the help of Model Builder tool (ArcGIS ${ }^{\varpi}$ 10.0.4, ESRI software). This tool operates mainly over raster information (raster-based model) and enables the programming of spatial operations (union, intersection, clipping features or even mathematical expressions applied between layers), in an automatic form reducing the calculation time over the geo-referenced maps, 
Table 3. Spatial information and criteria classes for GIS methodology.

\begin{tabular}{ccc}
\hline Soil occupation classification & Factor & Population percentile (\%) \\
\hline Very low populated & 0.5 & 40 \\
Low populated & 0.4 & 60 \\
Average populated & 0.3 & 80 \\
High populated & 0.2 & 95 \\
Very high populated & 0.1 & 99 \\
\hline
\end{tabular}

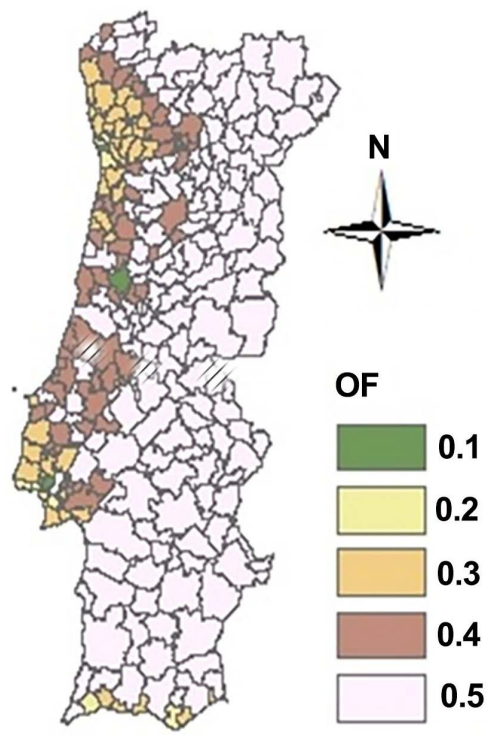

Figure 5. Spatial representation of the soil occupation classification (occupation factor).

which may be very long when large territories are under analysis. To perform the calculations a set of sub-models with the necessary operations and transformations was created.

The first sub-model treats for the operations concerned with restrictions between layers. This sub-model named "Define Restrictions" enables the definition of the restrictive layers and merges them into a raster dataset. This sub-model is also able to compute the terrain slope map and resample it according to the spatial resolutions of both wind energy and wind resource datasets, based on a digital elevation map. For the present case, the terrain slope, the Natural parks and "Natura 2000" areas were considered and conditions referred in 3.3 were applied. The output of this sub-model is used as an input information for the second sub-model. The second sub-model named "sustainable areas" refers to the application of the limits related to mean wind speed and wind energy maps according to the conditions described in 3.1. The third and fourth sub-models ("Sustainable Potential" and "Available Potential") are based on mathematical operations which compute the Equations (1) to (7). In particular the third sub-model, uses the soil occupation factors presented in 3.4 classified by municipality to obtain the sustainable wind potential and wind capacity still available 
for each municipality. Finally, the available wind potential is based on the sustainable wind potential obtained from the previous phase and on the installed wind capacity for each municipality.

\subsection{Toolbar Development}

In order to organize the calculations and make the procedures more efficient and less time consuming, a toolbar was developed containing all the sub-models. Therefore, the user is able to change the input data and criteria at any time and maintain, if necessary, the remaining calculations without changes, according to the objectives of the study. The procedures enable the identification of suitable areas for wind energy projects development, sustainable and available potential.

\section{Assessment of the Sustainable Wind Potential}

In this section the results provided by the toolbar "Wind Energy Planning" are presented for the Portuguese territory. Table 4 presents the values attributed to the input parameters for the current application, following Equations (1) to (5).

Figure 6(a) depicts the results obtained with the first sub-model "Define Restrictions" where the terrain's slope and the environmental restriction layers (Natural Parks and Natura 2000 areas) were used according to the assumed conditional information presented in Table 4 and Figure 6(b) shows the results from the second sub-model, "Sustainable Areas", where the outputs from the first sub-model were ingested and the conditional information from the mean wind speed, NEPs, and the environmental restrictions were applied.

The next step comes from the sub-model "Sustainable Potential". In this case the sub-model operates over the map presented in Figure 6(b) and applies to the restrictions expressed by the mathematical formulation according to Equations (1) to (7). For regional planning purposes, the method includes the municipalities' layer, to assess adequate areas for RE projects deployment inside each administrative region. It should be noted that soil occupation factors according to

Table 4. Parameter values used in GIS Methodology according to Equations (1) to (5).

\begin{tabular}{cc} 
Parameter & Value \\
\hline EL (energy losses) & 0.95 \\
Pot & 2.00 \\
$D$ & 80.00 \\
$d x, d y$ & 100.00 \\
$\delta x, \delta y$ & 5.00 \\
NEPs $(\mathrm{h} /$ year $)>$ & 2100.00 \\
Mean wind speed $(\mathrm{m} / \mathrm{s})>$ & 6.00 \\
Terrain slope $(\%)<$ & 20.00 \\
Release natural park area $(\%)$ & 2.00 \\
Release natural 2000 area $(\%)$ & 25.00
\end{tabular}




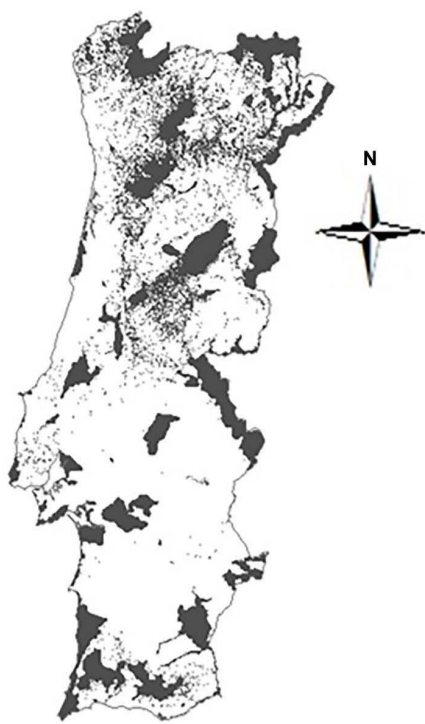

(a)

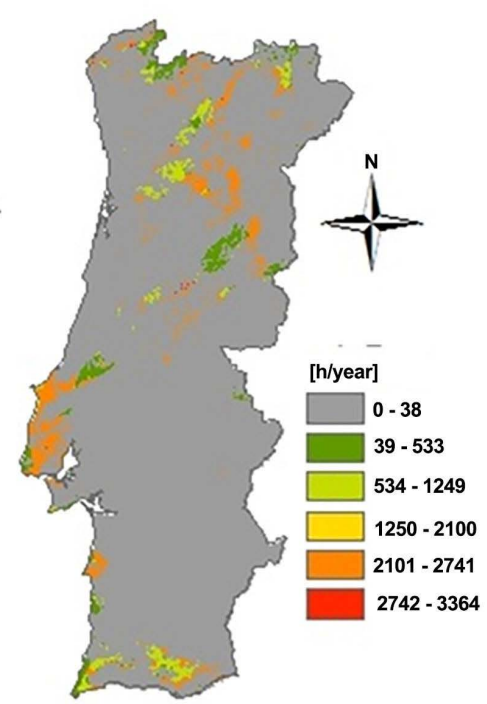

(b)

Figure 6. (a) Map with the environment and slope restrictions. (b) Suitable areas for wind park deployment over layed with NEPs values (h/year).

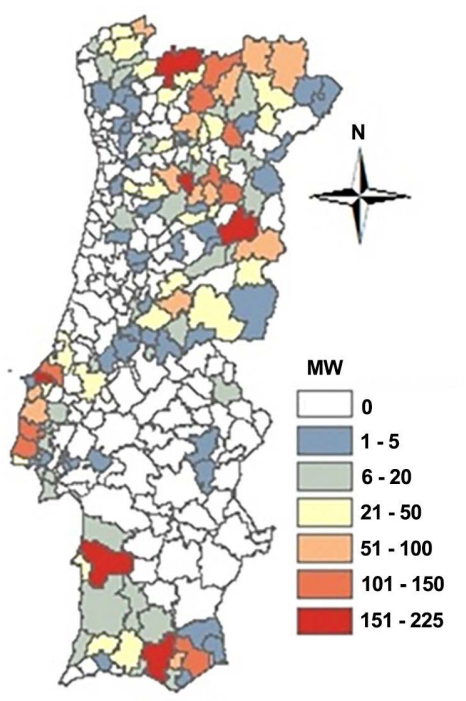

Figure 7. Available potential per municipality (MW).

Table 5. Sustainable available wind energy potential in continental Portugal (in MW).

\begin{tabular}{cccc}
\hline $\begin{array}{c}\text { Sustainable Wind } \\
\text { Potential (MW) }\end{array}$ & $\begin{array}{c}\text { NREAP Targets (2020) } \\
(\mathrm{MW})\end{array}$ & $\begin{array}{c}\text { Total Install Wind Cap. } \\
2017 \text { (MW) }\end{array}$ & $\begin{array}{c}\text { Available Wind } \\
\text { Pot. (MW) }\end{array}$ \\
\hline 6428 & 5273 & 5313 & 1115 \\
\hline
\end{tabular}

Figure 5 are applied in this step. Finally, the available potential per municipality can be estimated using the last sub-model "Available Potential”. Figure 7 presents the available potential for wind park deployment for each municipally. In this 
last sub-model, information about the already installed wind capacity in Portugal was used and Table 5 represents the results referred to the mainland territory considering the available information about the Portuguese onshore total operating wind parks at the end of 2017.

The results from Table 5 enable to conclude that the sustainable wind energy in Portugal is nearly 22\% upper than the fixed target in NREAP 2013 for 2020. Actually, the total installed capacity in the Country has overpassed the NREAP target and according the obtained results the available wind potential in the Mainland is circa $1115 \mathrm{MW}$ still available for newer wind power projects.

\section{Conclusion}

In this paper a methodology for the identification and quantification of the sustainable renewable potential using geographical information systems (GIS) was presented. The methodology was developed as a flexible tool to allow energy planners to test and alter RES conditions and restrictions in a simple and straightforward manner. The methodology was programmed and organized in a "toolbar" which enables the user to execute the sub-models developed for each phase of the planning process. The methodology is applied to the assessment of the available wind potential assessment in continental Portugal. This case study allows to illustrate the type of results that can be obtained and the added value of such a tool. Within a framework of sustainable development of the renewable energy sector, the concept and methodology presented can be applied to any geographic region where reliable information exists such as the wind resource map, geographic, environment and societal restrictions as minimum requirements to this methodology to evaluate successfully the sustainable wind potential for any region. Facing the new challenges imposed by the targets established in PNEC2030, new simulation with higher resolution and considering the repowering of old wind turbines, among other considerations, is undergoing.

\section{Acknowledgements}

The authors want to acknowledge to the Direção Geral de Energia e Geologia (DGEG) to provide the total wind capacity installed per administrative region for the year of 2017 and to the Instituto Nacional de Estatística (INE) and PORDATA website for providing relevant statistical data about the number of inhabitants per $\mathrm{km}$ squared for the 2017 year.

\section{Conflicts of Interest}

The authors declare no conflicts of interest regarding the publication of this paper.

\section{References}

[1] (2013) National Renewable Energy Action Plan-NREAP.

http://ec.europa.eu/energy/efficiency/eed/doc/reporting/2013/pt_2013report_en.pdf 
[2] (2018) Plano Nacional Integrado Energia E Clima 2021-2030.

https://ec.europa.eu/energy/sites/ener/files/documents/portugal_draftnecp.pdf

[3] Directive (EU) 2018/2001 of the European Parliament and of the Council of 11 December 2018 on the Promotion of the Use of Energy from Renewable Sources (Recast).

https://eur-lex.europa.eu/legal-content/EN/TXT/PDF/?uri=CELEX:32018L2001\&fr $\mathrm{om}=\mathrm{EN}$

[4] International Energy Agency (2013) IEA Wind 2013 Annual Report.

[5] IEA Wind TCP Annual Report 2017 for Portugal. https://community.ieawind.org/publications/ar

[6] Bravo, J., Casals, X. and Pascua, I. (2007) GIS Approach to the Definition of Capacity and Generation Ceilings of Renewable Energy Technologies. Energy Policy, 35, 4879-4892. https://doi.org/10.1016/j.enpol.2007.04.025

[7] Lopez, A., Roberts, B., Heimiller, D., Blair, N. and Porro, G. (2012) U.S. Renewable Energy Technical Potentials: A GIS-Based Analysis. Technical Report.

https://doi.org/10.2172/1219777

[8] Simões, T., Costa, P. and Estanqueiro, A. (2002) Desenvolvimento de Mapas de Vento em Portugal-Aplicação da Metodologia à Região Algarvia. Portuguese at XI Congresso Ibérico e VI Congresso Ibero-Americano de Energia Solar, Vilamoura, Portugal.

[9] Grassi, S., Chokani, N. and Abhari, R. (2012) Large Scale Technical and Economical Assessment of Wind Energy Potential with a GIS Tool: Case Study Iowa. Energy Policy, 45, 73-85. https://doi.org/10.1016/j.enpol.2012.01.061

[10] Simões, T. and Estanqueiro, A. (2000) Base de Dados do Potencial Energético do Vento em Portugal-EOLOS, CD-ROM Publication, INETI/DER.

[11] Brandão, R, Rio, J., Costa, P., Teixeira, J., Simões, T. and Estanqueiro, A. (2004) Base de Dados do Potencial Energético do Vento em Portugal-EOLOS 2.0. CD-ROM Publication, INETI/DER.

[12] Costa, P. (2004) Atlas do Potencial Eólico para Portugal Continental. Master Degree, Faculty of Sciences, University of Lisbon, Portugal.

[13] Costa, P. and Estanqueiro, A. (2004) Atlas do Potencial Eólico para Portugal Continental. CD-ROM Publication, INETI/DER.

[14] Costa, P., Miranda, P. and Estanqueiro, A. (2006) Development and Validation of the Portuguese Wind Atlas. Publication in the Proceedings of the European Wind Energy Conference (EWEC), Athens.

[15] Costa, P., Miranda, P. and Estanqueiro, A. (2006) Validation of the Portuguese Wind Atlas. Conference in Métodos Numéricos em Mecânica dos Fluidos e Termodinâmica, Faculty of Sciences and Technology, Monte da Caparica, Portugal.

[16] Costa, P. and Estanqueiro, A. (2006) Assessment of the Sustainable Offshore Wind Potential in Portugal. Publication in the Proceedings of the European Wind Energy Conference (EWEC), Athens.

[17] Simões, T., Costa, P. and Estanqueiro, A. (2008) A Methodology for the Identification of the Sustainable Wind Potential. The Portuguese Case Study. 2009 IEEE/PES Power Systems Conference and Exposition, Seattle, WA, 15-18 March 2009, 1-7. https://doi.org/10.1109/PSCE.2009.4839951

[18] Costa, P., Simões, T. and Estanqueiro, A. (2010) Sustainable Offshore Wind Potential in Continental Portugal. Proceedings of the Workshop "Oceans as a Source of energy", Academia de Engenharia, Berlin-Brandenburgische der Wissenschaften, Lisbon, Portugal, 40-43. 
[19] Farr, T.G., et al. (2007) The Shuttle Radar Topography Mission. Reviews of Geophysics, 45, RG2004. https://doi.org/10.1029/2005RG000183

[20] Rodriguez, E., Morris, C.S., Belz, J.E., Chapin, E.C., Martin, J.M., Daffer, W. and Hensley, S. (2005) An Assessment of the SRTM Topographic Products. Technical Report JPL D-31639, Jet Propulsion Laboratory, Pasadena, California, 143 p.

[21] Simiu, E. and Petersen, R.H. (1986) Wind Effects on Structures. Wiley Interscience, New York.

[22] Troen, I. and Petersen, E.L. (1989) European Wind Atlas. Riso National Laboratory. 